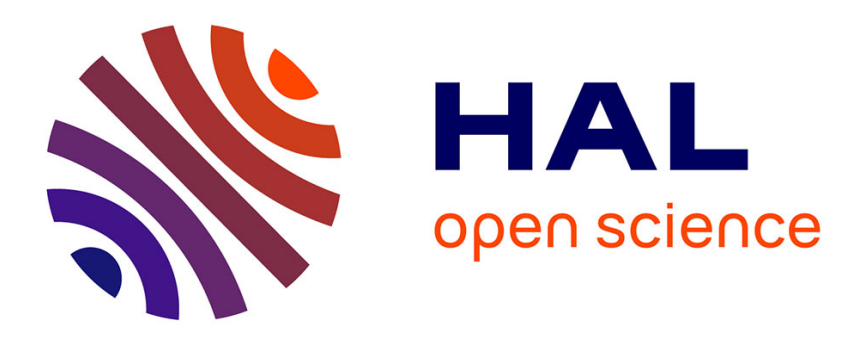

\title{
Complementarity bilateral bounds on forces in magnet systems
}

Alain Bossavit

\section{To cite this version:}

Alain Bossavit. Complementarity bilateral bounds on forces in magnet systems. 2006. hal-00170492

\section{HAL Id: hal-00170492 \\ https://hal.science/hal-00170492}

Preprint submitted on 8 Sep 2007

HAL is a multi-disciplinary open access archive for the deposit and dissemination of scientific research documents, whether they are published or not. The documents may come from teaching and research institutions in France or abroad, or from public or private research centers.
L'archive ouverte pluridisciplinaire HAL, est destinée au dépôt et à la diffusion de documents scientifiques de niveau recherche, publiés ou non, émanant des établissements d'enseignement et de recherche français ou étrangers, des laboratoires publics ou privés. 


\title{
Complementarity bilateral bounds on forces in magnet systems
}

Proceedings EPNC 2006, $19^{\text {th }}$ Symp. on Electromagnetic Phenomena in Nonlinear Circuits

(June 28-30, 2006, Maribor, Slovenia), PTETiS Publishers (Poznan), 2006, pp. 55-6.

\author{
Alain Bossavit \\ LGEP, 11 Rue Joliot-Curie, 91192 Gif-sur-Yvette CEDEX, France \\ Bossavit@lgep.supelec.fr
}

Abstract-It is well known that complementarity can provide bilateral bounds on energy, in numerical approximations of nonlinear magnetostatics. Force is, up to sign, the derivative of energy, so can such bounds also apply to forces, torques, etc.? On the face of it, no, since inequalities are not preserved by differentiation. Yet, useful bounds can be given in some cases, as shown here, following an idea by E. Matagne (2003).

\section{PRELIMINARIES}

We study nonlinear magnetostatic systems depending on a configuration parameter $\mathrm{u}$ that may describe, for instance, the translation or rotation of a part of the system relative to the rest of it. Figure 1 displays a concrete example.

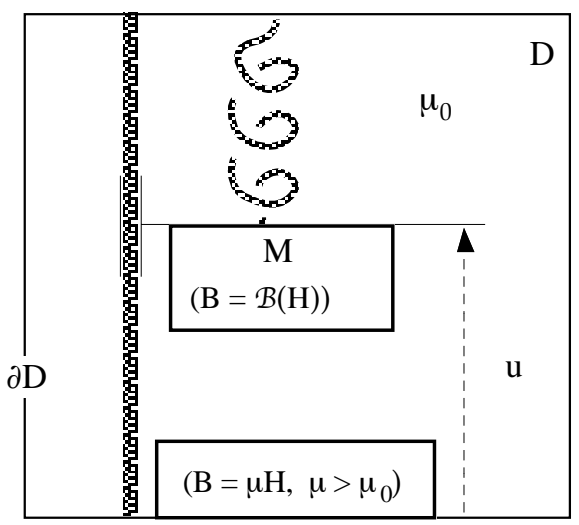

Fig. 1. Here, a single real kinematical parameter $u$. The magnet $M$, suspended by a spring, and characterized by its nonlinear $\mathrm{B}-\mathrm{H}$ law (no hysteresis), is attracted by a fixed ferromagnetic plate (at the bottom). On the computational domain's wall $\partial \mathrm{D}$, one has $\mathrm{n} \cdot \mathrm{B}=0$.

All vector fields evoked live in 3D real space, with scalar product " ." and norm | |, and are supposed to be square-integrable over the computational domain D. The abbreviation $(\mathrm{B}, \mathrm{H})$ will be used to denote the scalar product $\int_{\mathrm{D}} \mathrm{B} \cdot \mathrm{H}$. By "arginf $\{f(x): x \in X\}$ ", we mean "the (set of) minimizer(s) of $f$ over $X "$ ".

Before beginning in earnest, let us explain by example how the relation between $B$ and $H$ will be expressed. Suppose $M$ is a "hard magnet", characterized by a uniform vector-valued remanent induction $\mathrm{B}^{\mathrm{r}}$, pointing upwards in Fig. 1. The $\mathrm{B}-\mathrm{H}$ law is then $\mathrm{B}=\mu \mathrm{H}$ outside $\mathrm{M}$, with $\mu=\mu_{0}$ in the air, and $\mathrm{B}=\mu \mathrm{H}+\mathrm{B}^{\mathrm{r}}$ 
inside $M$. Call $M_{0}$ the part of $D$ occupied by $M$ when $u$ is equal to some reference value $\mathrm{u}_{0}$, and denote by $\mathrm{k}$ the unit upwards-directed vector. Now, for any given $\mathrm{u}$ and vector field $\mathrm{B}$ in $\mathrm{D}$, set

$$
\Psi(\mathrm{u}, \mathrm{B})=\int_{\mathrm{D}} \mathrm{dx}|\mathrm{B}(\mathrm{x})|^{2} / 2 \mu-\mu^{-1} \int_{\mathrm{M}_{0}} \mathrm{dx} \mathrm{B}\left(\mathrm{x}+\mathrm{k}\left(\mathrm{u}-\mathrm{u}_{0}\right)\right) \cdot \mathrm{B}^{\mathrm{r}},
$$

where $\mathrm{dx}$ is the volume element, and call this (the name can be justified, cf. (Bossavit 2004)) the magnetic energy of induction field $B$ in configuration $u$. The partial derivative with respect to $\mathrm{B}$ (what mathematicians call the "Fréchet derivative") is the vector field $\mathrm{H}$ such that $\Psi(\mathrm{u}, \mathrm{B}+\delta \mathrm{B})-\Psi(\mathrm{u}, \mathrm{B}) \approx \int_{\mathrm{D}} \mathrm{H} \cdot \delta \mathrm{B}$, up to higher order terms, for a small variation $\delta B$ of $B$. As an easy computation will show (differentiate under the summation sign with respect to $B$ ), one has $\mathrm{H}=$ $\left(B-B^{r}\right) / \mu$ in $M$, and $H=B / \mu$ outside $M$, so this vector field $H$ does indeed satisfy the B-H law. So the latter is expressed in one stroke, for the whole region, by the equality $\mathrm{H}=\partial_{\mathrm{B}} \Psi(\mathrm{u}, \mathrm{B})$. In a quite symmetrical way, there is a function $\Phi(\mathrm{u}, \mathrm{H})$, called magnetic coenergy (of $\mathrm{H}$ in configuration $\mathrm{u}$ ) such that $\mathrm{B}=$ $\partial_{\mathrm{H}} \Phi(\mathrm{u}, \mathrm{H})$ also expresses, in an equivalent way, the B-H relation. Functions $\Psi$ and $\Phi$ make an example of what is called, in Convex Analysis (Rockafellar, 1970), "a pair of conjugate lower semi-continuous convex functions", of B and $\mathrm{H}$ respectively, parameterized by $u$. (An on-line tutorial on convex analysis can be found at www.icm.edu.pl/edukacja/mat.php.) One easily verifies that

$$
\mathcal{F}_{\mathrm{u}}(\mathrm{B}, \mathrm{H}) \equiv \Psi(\mathrm{u}, \mathrm{B})+\Phi(\mathrm{u}, \mathrm{H})-(\mathrm{B}, \mathrm{H}) \geq 0
$$

whatever $\mathrm{B}$ and $\mathrm{H}$, with equality - this is the important point - when the $\mathrm{B}-\mathrm{H}$ law is satisfied. One says that energy and coenergy are complementary.

Remark. Even when $\Psi$ fails to be differentiable at "point" B, it is still true that $\mathrm{H} \in \partial_{\mathrm{B}} \Psi(\mathrm{u}, \mathrm{B})$, where the right-hand side denotes a set of vector fields, called the sub-differential of $\Psi$ at $\mathrm{B}$. Though this offers the precious possibility to deal with non-smooth B-H laws, the inclusion notation will be avoided here. $\diamond$

\section{COMPLEMENTARITY IN \\ NON-LINEAR MAGNETOSTATICS}

What precedes has general applicability: Given a pair $\Psi-\Phi$ of such conjugate functions, (1) always holds, and equality in (1) constitutes a global B-H law, dependent on $\mathrm{u}$, which expresses, in a single move, the constitutive laws for all materials included in domain $\mathrm{D}$, at all points. We shall work within this framework from now on. Note that $u$ may consist in several real parameters, and be a point in some "configuration manifold" $U$ (which could even have infinite dimension, as for instance when $\mathrm{u}$ stands for a displacement field). The formulation is powerful enough to cover deformable systems of magnetized bodies, including magnets and nonlinear ferromagnetic materials, with the restriction however that hysteresis is excluded. 
As for equations such as $\operatorname{div} \mathrm{B}=0, \operatorname{rot} \mathrm{H}=\mathrm{J}^{\mathrm{s}}$, boundary condition $\mathrm{n} \cdot \mathrm{B}=0$, etc., they are subsumed by the requirements $\mathrm{B} \in \mathrm{IB}^{\mathrm{s}}, \mathrm{H} \in \mathrm{IH}^{\mathrm{s}}$ (s for "source") where $\mathrm{IB}^{\mathrm{s}}$ and $\mathrm{IH}^{\mathrm{s}}$ are appropriate closed affine subspaces of $\mathrm{IL}^{2}(\mathrm{D})$. For instance, in Fig. $1, \mathrm{IB}^{\mathrm{s}}=\{\mathrm{B}: \operatorname{div} \mathrm{B}=0, \mathrm{n} \cdot \mathrm{B}=0\}$ and $\mathrm{IH}^{\mathrm{s}}=\{\mathrm{H}: \operatorname{rot} \mathrm{H}=0\}$ will do. (If a DC coil with given current density $\mathrm{J}^{\mathrm{s}}$ was contained in $\mathrm{D}$, the specification would be $\mathrm{IH}^{\mathrm{s}}=\left\{\mathrm{H}: \operatorname{rot} \mathrm{H}=\mathrm{J}^{\mathrm{s}}\right\}$. If a magnetic flux $\phi^{\mathrm{s}}$ was forced through a part of the wall $\partial \mathrm{D}$ by some external agency, $\mathrm{IB}^{\mathrm{s}}$ would be the subspace $\left\{\mathrm{B}: \operatorname{div} \mathrm{B}=0, \mathrm{n} \cdot \mathrm{B}=\phi^{\mathrm{s}}\right\}$.) The magnetostatics problem can then be expressed as, given $\mathrm{u}$, find $\{\mathrm{B}, \mathrm{H}\}$ such that $\mathrm{B} \in \mathrm{IB}^{\mathrm{s}}, \mathrm{H} \in \mathrm{IH}^{\mathrm{s}}$, and $\Psi(\mathrm{u}, \mathrm{B})+\Phi(\mathrm{u}, \mathrm{H})=$ $(\mathrm{B}, \mathrm{H})$. There is a solution (unique if $\Psi$ and $\Phi$ are strictly convex), given by

$$
\left\{\mathrm{B}^{\mathrm{u}}, \mathrm{H}^{\mathrm{u}}\right\}=\operatorname{arginf}\left\{\Psi\left(\mathrm{u}, \mathrm{B}^{\prime}\right)+\Phi\left(\mathrm{u}, \mathrm{H}^{\prime}\right)-\left(\mathrm{B}^{\prime}, \mathrm{H}^{\prime}\right): \mathrm{B}^{\prime} \in \mathrm{IB}^{\mathrm{s}}, \mathrm{H}^{\prime} \in \mathrm{IH}^{\mathrm{s}}\right\},
$$

a minimization problem which is equivalent to the pair of independent standard variational problems:

$$
\begin{aligned}
& \mathrm{B}^{\mathrm{u}}=\operatorname{arginf}\left\{\Psi\left(\mathrm{u}, \mathrm{B}^{\prime}\right)-\left(\mathrm{B}^{\prime}, \mathrm{H}^{\mathrm{s}}\right): \mathrm{B}^{\prime} \in \mathrm{IB}^{\mathrm{s}}\right\}, \\
& \mathrm{H}^{\mathrm{u}}=\operatorname{arginf}\left\{\Phi\left(\mathrm{u}, \mathrm{H}^{\prime}\right)-\left(\mathrm{B}^{\mathrm{s}}, \mathrm{H}^{\prime}\right): \mathrm{H}^{\prime} \in \mathrm{IH}^{\mathrm{s}}\right\},
\end{aligned}
$$

where $\mathrm{H}^{\mathrm{s}}$ and $\mathrm{B}^{\mathrm{s}}$ are arbitrarily picked in $\mathrm{IH}^{\mathrm{s}}$ and $\mathrm{IB}^{\mathrm{s}}$ respectively. This uncoupling results from the orthogonality of subspaces $\mathrm{IH}^{0}$ and $\mathrm{IB}^{0}$, which implies

$$
\left(\mathrm{B}^{\prime}-\mathrm{B}^{\mathrm{s}}, \mathrm{H}^{\prime}-\mathrm{H}^{\mathrm{s}}\right)=0 \quad \forall \mathrm{B}^{\prime} \in \mathrm{IB}^{\mathrm{s}}, \quad \mathrm{H}^{\prime} \in \mathrm{IH}^{\mathrm{s}},
$$

which in particular entails, for the solution $\left\{\mathrm{B}^{\mathrm{u}}, \mathrm{H}^{\mathrm{u}}\right\}$,

$$
\left(\mathrm{B}^{\mathrm{u}}-\mathrm{B}^{\mathrm{s}}, \mathrm{H}^{\mathrm{u}}-\mathrm{H}^{\mathrm{s}}\right)=0,
$$

an equality (known as Tellegen's theorem in the electrical engineering literature (Penfield et al. 1970)) which holds whatever the B-H law.

Suppose now (2) or (3) are solved by internal approximation, Galerkin style: one replaces $\mathrm{IB}^{\mathrm{s}}$ and $\mathrm{IH}^{\mathrm{s}}$ by finite-dimensional affine subspaces $\mathrm{IB}_{m}^{\mathrm{s}}$ and $\mathrm{IH}^{\mathrm{s}}$ ( $m$ may stand for "mesh", or "method"), and one calls $\mathrm{B}_{m}^{\mathrm{u}}$ and $\mathrm{H}_{m}^{\mathrm{u}}$ the minimizers. Then, the approximate solutions $\mathrm{B}^{\mathrm{u}}{ }_{m}$ and $\mathrm{H}^{\mathrm{u}}{ }_{m}$ satisfy:

$$
\begin{aligned}
& \Psi\left(\mathrm{u}, \mathrm{B}_{m}^{\mathrm{u}}\right)-\left(\mathrm{B}^{\mathrm{u}}{ }_{m}, \mathrm{H}^{\mathrm{s}}\right) \geq \Psi\left(\mathrm{u}, \mathrm{B}^{\mathrm{u}}\right)-\left(\mathrm{B}^{\mathrm{u}}, \mathrm{H}^{\mathrm{s}}\right), \\
& \Phi\left(\mathrm{u}, \mathrm{H}_{m}^{\mathrm{u}}\right)-\left(\mathrm{B}^{\mathrm{s}}, \mathrm{H}_{m}^{\mathrm{u}}\right) \geq \Phi\left(\mathrm{u}, \mathrm{H}^{\mathrm{u}}\right)-\left(\mathrm{B}^{\mathrm{s}}, \mathrm{H}^{\mathrm{u}}\right) .
\end{aligned}
$$

Proposition 1. One has

$$
\mathcal{F}_{\mathrm{u}}\left(\mathrm{B}^{\mathrm{u}}{ }_{m}, \mathrm{H}_{m}^{\mathrm{u}}\right)=\mathcal{F}_{\mathrm{u}}\left(\mathrm{B}^{\mathrm{u}}, \mathrm{H}_{m}^{\mathrm{u}}\right)+\mathcal{F}_{\mathrm{u}}\left(\mathrm{B}^{\mathrm{u}}{ }_{m}, \mathrm{H}^{\mathrm{u}}\right) .
$$

Proof. Add the quantities $\Psi\left(\mathrm{B}^{\mathrm{u}}{ }_{m}\right)+\Phi\left(\mathrm{H}^{\mathrm{u}}\right)-\left(\mathrm{B}^{\mathrm{u}}{ }_{m}, \mathrm{H}^{\mathrm{u}}\right)$ and $\Psi\left(\mathrm{B}^{\mathrm{u}}\right)+\Phi\left(\mathrm{H}_{m}^{\mathrm{u}}\right)-\left(\mathrm{B}^{\mathrm{u}}\right.$, $\left.\mathrm{H}^{\mathrm{u}}{ }_{m}\right)$, subtract the null quantity $\Psi\left(\mathrm{B}^{\mathrm{u}}\right)+\Phi\left(\mathrm{H}^{\mathrm{u}}\right)-\left(\mathrm{B}^{\mathrm{u}}, \mathrm{H}^{\mathrm{u}}\right)$, and use $\left(\mathrm{B}^{\mathrm{u}}{ }_{m}-\mathrm{B}^{\mathrm{u}}, \mathrm{H}^{\mathrm{u}}{ }_{m}-\right.$ $\left.\mathrm{H}^{\mathrm{u}}\right)=0$, which stems from (4). [This is a nonlinear generalization of Synge's "hypercircle" result (Synge 1957), recalled on Fig. 2.] $\diamond$ 


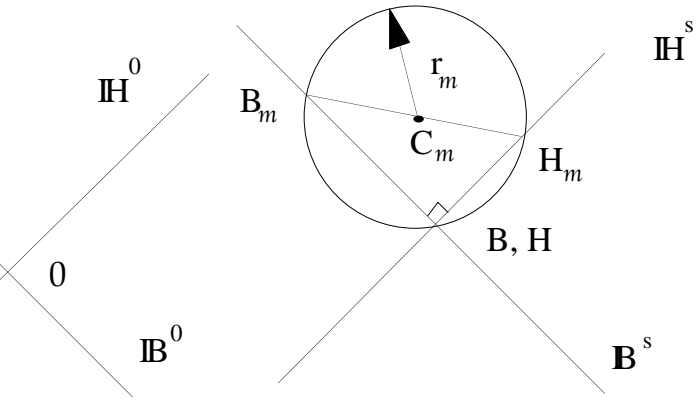

Fig. 2. Synge's hypercircle, assuming $\mu=1$ all over for simplicity. (The figure's plane is supposed to represent the functional space $\mathrm{IL}^{2}(\mathrm{D})$. Parameter $\mathrm{u}$ omitted and understood.) In that case, $\mathrm{B}=\mathrm{H}$, and this unknown field lies on the "hypercircle" centered at $\mathrm{C}_{m}=\left(\mathrm{H}_{m}+\mathrm{B}_{m}\right) / 2$, where $\mathrm{H}_{m}$ and $\mathrm{B}_{m}$ are the computed approximations of $\mathrm{H}$ and $\mathrm{B}$, with radius $\mathrm{r}_{m}$ such that $\left|\mathrm{B}_{m}-\mathrm{H}_{m}\right|^{2}=4 \mathrm{r}_{m}{ }^{2}$. Here, (8) is $1 / 2\left|\mathrm{~B}_{m}-\mathrm{H}_{m}\right|^{2}=1 / 2\left|\mathrm{~B}_{m}-\mathrm{B}\right|^{2}+1 / 2\left|\mathrm{H}_{m}-\mathrm{H}\right|^{2}$.

\section{Proposition 2. One has}

$$
\begin{aligned}
& -\Psi\left(\mathrm{u}, \mathrm{B}_{m}^{\mathrm{u}}\right)+\left(\mathrm{B}_{m}^{\mathrm{u}}-\mathrm{B}^{\mathrm{s}}, \mathrm{H}^{\mathrm{s}}\right) \leq \Phi\left(\mathrm{u}, \mathrm{H}^{\mathrm{u}}\right)-\left(\mathrm{B}^{\mathrm{s}}, \mathrm{H}^{\mathrm{u}}\right) \leq \Phi\left(\mathrm{u}, \mathrm{H}_{m}^{\mathrm{u}}\right)-\left(\mathrm{B}^{\mathrm{s}}, \mathrm{H}^{\mathrm{u}}{ }_{m}\right) . \\
& -\Phi\left(\mathrm{u}, \mathrm{H}_{m}^{\mathrm{u}}\right)+\left(\mathrm{B}^{\mathrm{s}}, \mathrm{H}_{m}^{\mathrm{u}}-\mathrm{H}^{\mathrm{s}}\right) \leq \Psi\left(\mathrm{u}, \mathrm{B}^{\mathrm{u}}\right)-\left(\mathrm{B}^{\mathrm{u}}, \mathrm{H}^{\mathrm{s}}\right) \leq \Psi\left(\mathrm{u}, \mathrm{B}_{m}^{\mathrm{u}}\right)-\left(\mathrm{B}_{m}^{\mathrm{u}}{ }_{m} \mathrm{H}^{\mathrm{s}}\right) .
\end{aligned}
$$

Proof. By (5), one has

$$
\Psi\left(\mathrm{u}, \mathrm{B}^{\mathrm{u}}\right)-\left(\mathrm{B}^{\mathrm{u}}, \mathrm{H}^{\mathrm{s}}\right)+\Phi\left(\mathrm{u}, \mathrm{H}^{\mathrm{u}}\right)-\left(\mathrm{B}^{\mathrm{s}}, \mathrm{H}^{\mathrm{u}}\right)+\left(\mathrm{B}^{\mathrm{s}}, \mathrm{H}^{\mathrm{s}}\right)=0,
$$

which yields, thanks to (6), the first inequality in (9). The second inequality is (6). Symmetrically, (10) holds. $\diamond$

Let us now define $\Phi^{\mathrm{s}}(\mathrm{u})=\Phi\left(\mathrm{u}, \mathrm{H}^{\mathrm{u}}\right)-\left(\mathrm{B}^{\mathrm{s}}, \mathrm{H}^{\mathrm{u}}\right)$ and $\Psi^{\mathrm{s}}(\mathrm{u})=\Psi\left(\mathrm{u}, \mathrm{B}^{\mathrm{u}}\right)-$ $\left(\mathrm{B}^{\mathrm{u}}, \mathrm{H}^{\mathrm{s}}\right)$. This prompts us to also define $\Phi_{m}^{\mathrm{s}}(\mathrm{u})=\Phi\left(\mathrm{u}, \mathrm{H}_{m}^{\mathrm{u}}\right)-\left(\mathrm{B}^{\mathrm{s}}, \mathrm{H}_{m}^{\mathrm{u}}\right)$ and $\Psi_{m}^{\mathrm{s}}(\mathrm{u})=\Psi\left(\mathrm{u}, \mathrm{B}_{m}^{\mathrm{u}}\right)-\left(\mathrm{B}_{m}^{\mathrm{u}}, \mathrm{H}^{\mathrm{s}}\right)$. Bounds (9) and (10) take then a more compact form:

$$
\begin{aligned}
& -\Psi_{m}^{\mathrm{s}}(\mathrm{u})-\left(\mathrm{B}^{\mathrm{s}}, \mathrm{H}^{\mathrm{s}}\right) \leq \Phi^{\mathrm{s}}(\mathrm{u}) \leq \Phi_{m}^{\mathrm{s}}(\mathrm{u}), \\
& -\Phi_{m}^{\mathrm{s}}(\mathrm{u})-\left(\mathrm{B}^{\mathrm{s}}, \mathrm{H}^{\mathrm{s}}\right) \leq \Psi^{\mathrm{s}}(\mathrm{u}) \leq \Psi_{m}^{\mathrm{s}}(\mathrm{u}) .
\end{aligned}
$$

Proposition 3. One has

$$
\begin{aligned}
& \Psi_{m}^{\mathrm{s}}(\mathrm{u})+\Phi_{m}^{\mathrm{s}}(\mathrm{u})=\mathcal{F}_{\mathrm{u}}\left(\mathrm{B}_{m}^{\mathrm{u}}{ }_{m}, \mathrm{H}^{\mathrm{u}}{ }_{m}\right)-\left(\mathrm{B}^{\mathrm{s}}, \mathrm{H}^{\mathrm{s}}\right), \\
& \Psi^{\mathrm{s}}(\mathrm{u})+\Phi^{\mathrm{s}}(\mathrm{u})=-\left(\mathrm{B}^{\mathrm{s}}, \mathrm{H}^{\mathrm{s}}\right) .
\end{aligned}
$$

Proof. By definition, $\Phi_{m}^{\mathrm{s}}(\mathrm{u})+\Psi_{m}^{\mathrm{s}}(\mathrm{u})$ is

$$
\begin{aligned}
\Phi\left(\mathrm{u}, \mathrm{H}^{\mathrm{u}}{ }_{m}\right)+\Psi\left(\mathrm{u}, \mathrm{B}^{\mathrm{u}}{ }_{m}\right)-\left(\mathrm{B}^{\mathrm{s}}, \mathrm{H}^{\mathrm{u}}{ }_{m}\right)-\left(\mathrm{B}^{\mathrm{u}}{ }_{m}, \mathrm{H}^{\mathrm{s}}\right) \\
=\mathcal{F}_{\mathrm{u}}\left(\mathrm{B}^{\mathrm{u}}{ }_{m}, \mathrm{H}_{m}^{\mathrm{u}}\right)+\left(\mathrm{B}^{\mathrm{u}}{ }_{m}, \mathrm{H}^{\mathrm{u}}{ }_{m}\right)-\left(\mathrm{B}^{\mathrm{s}}, \mathrm{H}^{\mathrm{u}}{ }_{m}\right)-\left(\mathrm{B}^{\mathrm{u}}{ }_{m}, \mathrm{H}^{\mathrm{s}}\right) \\
=\mathcal{F}_{\mathrm{u}}\left(\mathrm{B}^{\mathrm{u}}{ }_{m}, \mathrm{H}^{\mathrm{u}}{ }_{m}\right)+\left(\mathrm{B}^{\mathrm{u}}{ }_{m}-\mathrm{B}^{\mathrm{s}}, \mathrm{H}^{\mathrm{u}}{ }_{m}-\mathrm{H}^{\mathrm{s}}\right)-\left(\mathrm{B}^{\mathrm{s}}, \mathrm{H}^{\mathrm{s}}\right) \\
=\mathcal{F}_{\mathrm{u}}\left(\mathrm{B}^{\mathrm{u}}{ }_{m}, \mathrm{H}^{\mathrm{u}}{ }_{m}\right)-\left(\mathrm{B}^{\mathrm{s}}, \mathrm{H}^{\mathrm{s}}\right),
\end{aligned}
$$


thanks to (4). The same computation "without $m$ ", in which case $\mathcal{F}_{\mathrm{u}}\left(\mathrm{B}^{\mathrm{u}}, \mathrm{H}^{\mathrm{u}}\right)=0$, yields (14). $\diamond$

Subtracting (14) from (13) gives the following alternatives to (11)(12):

$$
\begin{gathered}
\Phi_{m}^{\mathrm{s}}(\mathrm{u})-\mathcal{F}_{\mathrm{u}}\left(\mathrm{B}^{\mathrm{u}}{ }_{m}, \mathrm{H}^{\mathrm{u}}{ }_{m}\right) \leq \Phi^{\mathrm{s}}(\mathrm{u}) \leq \Phi_{m}^{\mathrm{s}}(\mathrm{u}), \\
\Psi_{m}^{\mathrm{s}}(\mathrm{u})-\mathcal{F}_{\mathrm{u}}\left(\mathrm{B}^{\mathrm{u}}{ }_{m}, \mathrm{H}_{m}^{\mathrm{u}}\right) \leq \Psi^{\mathrm{s}}(\mathrm{u}) \leq \Psi_{m}^{\mathrm{s}}(\mathrm{u}) .
\end{gathered}
$$

In what follows, $\partial_{\mathrm{u}} \Phi$ and $\partial_{\mathrm{H}} \Phi$ denote the partial derivatives of $\Phi$ with respect to its two arguments. Similar notation about $\Psi$. Let's stress, to avoid any possible confusion, that $\partial_{\mathrm{u}} \Phi\left(\mathrm{u}, \mathrm{H}^{\mathrm{u}}\right)$, which is the value assumed by the partial derivative $\partial_{u} \Phi$ when its arguments take the values $u$ and $\mathrm{H}^{\mathrm{u}}$, should not be mistaken for the derivative of the function $\mathrm{u} \rightarrow \Phi\left(\mathrm{u}, \mathrm{H}^{\mathrm{u}}\right)$. (The confusion is all the more likely that these two derivatives actually assume the same values when $\mathrm{B}^{\mathrm{s}}=0$, which is most often the case in practice, whereas $\mathrm{H}^{\mathrm{s}} \neq 0$, as a rule.) One has:

Proposition 4. $\partial \Phi^{\mathrm{s}}(\mathrm{u})=\partial_{\mathrm{u}} \Phi\left(\mathrm{u}, \mathrm{H}^{\mathrm{u}}\right), \quad \partial \Psi^{\mathrm{s}}(\mathrm{u})=\partial_{\mathrm{u}} \Psi\left(\mathrm{u}, \mathrm{B}^{\mathrm{u}}\right)$.

Proof. By the chain rule,

$$
\partial \Phi^{\mathrm{s}}(\mathrm{u})=\partial_{\mathrm{u}} \Phi\left(\mathrm{u}, \mathrm{H}^{\mathrm{u}}\right)+\left(\partial_{\mathrm{H}} \Phi\left(\mathrm{u}, \mathrm{H}^{\mathrm{u}}\right)-\mathrm{B}^{\mathrm{s}}, \partial_{\mathrm{u}} \mathrm{H}^{\mathrm{u}}\right) .
$$

Since $\mathrm{H}^{\mathrm{u}}$ stays in $\mathrm{IH}^{\mathrm{s}}$ whatever $\mathrm{u}$, its derivative $\partial_{\mathrm{u}} \mathrm{H}^{\mathrm{u}}$ is in $\mathrm{IH}^{0}$, and $\partial_{\mathrm{H}} \Phi\left(\mathrm{u}, \mathrm{H}^{\mathrm{u}}\right)$ $\equiv \mathrm{B}^{\mathrm{u}} \in \mathrm{IB}^{\mathrm{s}}$, hence the result by orthogonality of $\mathrm{IB}^{0}$ and $\mathrm{IH}^{0}$, and same thing for $\partial \Psi^{\mathrm{s}}(\mathrm{u}) . \diamond$

Proposition 5. For a fixed $m, \partial \Phi_{m}^{\mathrm{s}}(\mathrm{u})=\partial_{\mathrm{u}} \Phi\left(\mathrm{u}, \mathrm{H}_{m}^{\mathrm{u}}\right), \partial \Psi_{m}^{\mathrm{s}}(\mathrm{u})=\partial_{\mathrm{u}} \Psi\left(\mathrm{u}, \mathrm{B}_{m}^{\mathrm{u}}\right)$.

Proof. $\partial \Psi_{m}^{\mathrm{s}}(\mathrm{u})=\partial_{\mathrm{u}} \Psi\left(\mathrm{u}, \mathrm{B}^{\mathrm{u}}{ }_{m}\right)-\left(\partial_{\mathrm{B}} \Psi\left(\mathrm{u}, \mathrm{B}^{\mathrm{u}}{ }_{m}\right)-\mathrm{H}^{\mathrm{s}}, \partial_{\mathrm{u}} \mathrm{B}_{m}^{\mathrm{u}}\right) \equiv \partial_{\mathrm{u}} \Psi\left(\mathrm{u}, \mathrm{B}^{\mathrm{u}}{ }_{m}\right)$, because $\mathrm{B}^{\mathrm{u}}{ }_{m}$ solves $\mathrm{B}^{\mathrm{u}}{ }_{m}=\operatorname{arginf}\left\{\Psi\left(\mathrm{u}, \mathrm{B}^{\prime}\right)-\left(\mathrm{H}^{\mathrm{s}}, \mathrm{B}^{\prime}\right): \mathrm{B}^{\prime} \in \mathrm{IB}_{m}^{\mathrm{s}}\right\}$, and $\partial_{\mathrm{u}} \mathrm{B}^{\mathrm{u}}{ }_{m} \in \mathrm{IB}^{0}$. $\diamond$

\section{FORCES}

As one knows (a proof adapted to the present context can be found in (Bossavit 2004)), force is $\mathrm{f}=\partial_{\mathrm{u}} \Phi\left(\mathrm{u}, \mathrm{H}^{\mathrm{u}}\right)$, i.e., the partial derivative of magnetic coenergy with respect to the configuration variable. (No need to add "while keeping currents constant": Taking the partial derivative with respect to $\mathrm{u}$ does mean that the second variable, $\mathrm{H}^{\mathrm{u}}$, "doesn't change" in the process, so the currents rot $\mathrm{H}^{\mathrm{u}}$ "do not change" either.) Alternatively, $\mathrm{f}=-\partial_{\mathrm{u}} \Psi\left(\mathrm{u}, \mathrm{B}^{\mathrm{u}}\right)$, as one can see by differentiating the equality $\Psi\left(\mathrm{u}, \mathrm{B}^{\mathrm{u}}\right)+\Phi\left(\mathrm{u}, \mathrm{H}^{\mathrm{u}}\right)-\left(\mathrm{B}^{\mathrm{u}}, \mathrm{H}^{\mathrm{u}}\right)=0$ with respect to $\mathrm{u}$ : Indeed, this gives, by applying the chain rule,

$$
\begin{aligned}
0 & =\partial_{\mathrm{u}} \Psi\left(\mathrm{u}, \mathrm{B}^{\mathrm{u}}\right)+\partial_{\mathrm{B}} \Psi\left(\mathrm{u}, \mathrm{B}^{\mathrm{u}}\right) \cdot \partial_{\mathrm{u}} \mathrm{B}^{\mathrm{u}} \\
& +\partial_{\mathrm{u}} \Phi\left(\mathrm{u}, \mathrm{H}^{\mathrm{u}}\right)+\partial_{\mathrm{H}} \Phi\left(\mathrm{u}, \mathrm{H}^{\mathrm{u}}\right) \cdot \partial_{\mathrm{u}} \mathrm{H}^{\mathrm{u}}-\left(\partial_{\mathrm{u}} \mathrm{B}^{\mathrm{u}}, \mathrm{H}^{\mathrm{u}}\right)-\left(\mathrm{B}^{\mathrm{u}}, \partial_{\mathrm{u}} \mathrm{H}^{\mathrm{u}}\right) \\
= & \partial_{\mathrm{u}} \Psi\left(\mathrm{u}, \mathrm{B}^{\mathrm{u}}\right)+\partial_{\mathrm{u}} \Phi\left(\mathrm{u}, \mathrm{H}^{\mathrm{u}}\right),
\end{aligned}
$$

since $\partial_{\mathrm{B}} \Psi\left(\mathrm{u}, \mathrm{B}^{\mathrm{u}}\right)=\mathrm{H}^{\mathrm{u}}$ and $\partial_{\mathrm{H}} \Phi\left(\mathrm{u}, \mathrm{H}^{\mathrm{u}}\right)=\mathrm{B}^{\mathrm{u}}$. 
What Prop. 4 establishes, therefore, is the existence of a "function of forces", namely $\Phi^{\mathrm{s}}$, or alternatively, $-\Psi^{\mathrm{s}}$, from which $\mathrm{f}$ derives. This is very useful in problems such as the one of Fig. 1, where the elastic force also derives from a similar function, say $\mathrm{u} \rightarrow \mathrm{E}(\mathrm{u})$. Equilibrium occurs when the two forces balance, $\partial_{\mathrm{u}} \mathrm{E}(\mathrm{u})=\partial \Phi^{\mathrm{s}}(\mathrm{u})$, or $\partial_{\mathrm{u}} \mathrm{E}(\mathrm{u})=-\partial \Psi^{\mathrm{s}}(\mathrm{u})$, and is therefore found by looking for the critical points of the function $\mathrm{u} \rightarrow \mathrm{E}(\mathrm{u})+\Psi^{\mathrm{s}}(\mathrm{u})$. Now, $\Psi$ depends on $\mathrm{B}$, which depends on $\mathrm{u}$, so it may be a good idea to minimize with respect to both $\mathrm{u}$ and $\mathrm{B}$. Indeed ("argcrit" stands for "the critical point of", assumed to be unique),

Proposition 6. The coupled problem ("magnetoelasticity") is

$$
\left\{\mathrm{u}, \mathrm{B}^{\mathrm{u}}\right\}=\operatorname{argcrit}\left\{\mathrm{E}\left(\mathrm{u}^{\prime}\right)+\Psi\left(\mathrm{u}^{\prime}, \mathrm{B}^{\prime}\right)-\left(\mathrm{B}^{\prime}, \mathrm{H}^{\mathrm{s}}\right): \mathrm{u}^{\prime} \in \mathrm{U}, \mathrm{B}^{\prime} \in \mathrm{IB}^{\mathrm{s}}\right\}
$$

It may come as a surprise that minimizing the total energy (elastic plus magnetic) won't work, if $\mathrm{H}^{\mathrm{s}} \neq 0$. But one would not be dealing with an isolated system in such a case. The "complementary" alternative to (15), solving $\partial_{\mathrm{u}} \mathrm{E}(\mathrm{u})=\partial \Phi^{\mathrm{s}}(\mathrm{u})$ with respect to $\mathrm{u}$, amounts to $\left\{\mathrm{u}, \mathrm{H}^{\mathrm{u}}\right\}=\operatorname{argcrit}\left\{\mathrm{E}\left(\mathrm{u}^{\prime}\right)-\Phi\left(\mathrm{u}^{\prime}, \mathrm{H}^{\prime}\right)+\left(\mathrm{B}^{\mathrm{s}}, \mathrm{H}^{\prime}\right)\right.$ : $\left.\mathrm{u}^{\prime} \in \mathrm{U}, \mathrm{H}^{\prime} \in \mathrm{IH}^{\mathrm{s}}\right\}$. It happens that, in many cases, $\mathrm{B}^{\mathrm{s}}=0$, which makes the alternative form attractive: One looks for the critical point(s) of $\mathrm{u} \rightarrow \mathrm{E}(\mathrm{u})-$ $\Phi\left(\mathrm{u}, \mathrm{H}^{\mathrm{u}}\right)$, then, and the simpler nature of this problem (concerned with a scalar magnetic potential rather than a vector one) often makes one prefer it to (15). But the presence of the minus sign is a great source of confusion: It looks like one had to minimize the difference between two energies.

Remark. The risk of confusion is highest in the linear case, where $\mathrm{B}=\mu_{\mathrm{u}} \mathrm{H}$, with a permeability $\mu_{u}$ that depends on $u$, but not on the local value of the field. Then, $\Phi\left(\mathrm{u}, \mathrm{H}^{\mathrm{u}}\right)=1 /{ }_{2} \int \mu_{\mathrm{u}}\left|\mathrm{H}^{\mathrm{u}}\right|^{2} \equiv{ }_{1}^{1 / 2} \int v_{\mathrm{u}}\left|\mathrm{B}^{\mathrm{u}}\right|^{2} \equiv{ }_{1}^{1} \int \mathrm{B}^{\mathrm{u}} \cdot \mathrm{H}^{\mathrm{u}}$ just happens to equal the energy of the magnetic field, which is $\Psi\left(\mathrm{u}, \mathrm{B}^{\mathrm{u}}\right) \equiv\left(\mathrm{B}^{\mathrm{u}}, \mathrm{H}^{\mathrm{u}}\right)-\Phi\left(\mathrm{u}, \mathrm{H}^{\mathrm{u}}\right)$, quite different from $\Phi\left(\mathrm{u}, \mathrm{H}^{\mathrm{u}}\right)$ in the general case. $\diamond$

We now restrict to the case when $\mathrm{u}$ is a single real parameter taking its value in an interval $[\mathrm{a}, \mathrm{b}]$. Let $\left\{\mathrm{H}^{\mathrm{u}}, \mathrm{B}^{\mathrm{u}}\right\} \quad$ [resp. $\left\{\mathrm{H}^{\mathrm{u}}{ }_{m}, \mathrm{~B}^{\mathrm{u}}{ }_{m}\right\}$, where $\mathrm{u}=\mathrm{a}$ or $\mathrm{b}$, denote the exact [resp. approximate] magnetostatics solutions for $\mathrm{u}=\mathrm{a}$ and $\mathrm{u}=\mathrm{b}$. What about the estimations of force via these computed values?

Let us define $\mathrm{f}^{\mathrm{u}}=\partial_{\mathrm{u}} \Phi\left(\mathrm{u}, \mathrm{H}^{\mathrm{u}}\right) \equiv-\partial_{\mathrm{u}} \Psi\left(\mathrm{u}, \mathrm{B}^{\mathrm{u}}\right)$, and let

$$
{ }^{\mathrm{H}} \mathrm{f}_{m}^{\mathrm{u}}=\partial_{\mathrm{u}} \Phi\left(\mathrm{u}, \mathrm{H}^{\mathrm{u}}{ }_{m}\right), \quad{ }^{\mathrm{B}} \mathrm{f}_{m}^{\mathrm{u}}=-\partial_{\mathrm{u}} \Psi\left(\mathrm{u}, \mathrm{B}^{\mathrm{u}}{ }_{m}\right),
$$

stand for the two corresponding approximations. (Of course, they need not coincide.) As a rule, $\partial_{\mathrm{u}} \Phi$ and $\partial_{\mathrm{u}} \Psi$ are known analytically if $\Phi$ and $\Psi$ themselves are, so these formulas can be applied in numerical work. No need to further approximate ${ }^{\mathrm{H}} \mathrm{f}_{m}^{\mathrm{u}}$ by a differential quotient such as

$$
{ }^{\mathrm{H}} \mathrm{f}_{m}^{\mathrm{u}} \sim\left[\Phi\left(\mathrm{b}, \mathrm{H}^{\mathrm{b}}{ }_{m}\right)-\Phi\left(\mathrm{a}, \mathrm{H}^{\mathrm{a}}{ }_{m}\right)\right] /(\mathrm{b}-\mathrm{a}),
$$

which would imply two computations of $\mathrm{H}^{\mathrm{u}}{ }_{m}$ where one suffices. This alleged 
necessity to compute twice (in the case of a single parameter, and $\mathrm{n}+1$ times, if $\mathrm{U}$ has dimension $\mathrm{n}$ ) is the basis of criticisms found scattered in the literature against the "virtual principle approach" to forces, deemed "expensive" for this reason. Such claims continue to appear in print nowadays, in spite of early debunking by Coulomb (1982) of this misconception.

With now a more ambitious agenda - see whether bilateral bounds for the force can be obtained - we shall try to exploit the bounds (11) and (12) established above. Since, by Props 4 and 5, ${ }^{\mathrm{B}} \mathrm{f}_{m}^{\mathrm{u}}=-\partial \Psi_{m}^{\mathrm{s}}(\mathrm{u}), \quad \mathrm{f}^{\mathrm{u}}=-\partial \Psi^{\mathrm{s}}(\mathrm{u})=\partial \Phi^{\mathrm{s}}(\mathrm{u})$, and ${ }^{\mathrm{H}} \mathrm{f}_{m}^{\mathrm{u}}{ }_{m}=$ $\partial \Phi_{m}^{\mathrm{s}}(\mathrm{u})$, one is tempted to differentiate (11) or (12), in hope of something like, for instance, ${ }^{\mathrm{B}} \mathrm{f}_{m}^{\mathrm{u}} \leq \mathrm{f}^{\mathrm{u}} \leq{ }^{\mathrm{H}} \mathrm{f}_{m}^{\mathrm{u}}$. Pure illusion, as inequalities don't survive differentiation, as a rule.

\section{COMPLEMENTARITY BOUNDS ON FORCES?}

Yet, as regards average force, we have

$$
\begin{aligned}
\langle\mathrm{f}\rangle=\left[\int_{\mathrm{a}}^{\mathrm{b}} \partial_{\mathrm{u}} \Phi\left(\mathrm{u}, \mathrm{H}^{\mathrm{u}}\right)\right] /(\mathrm{b}-\mathrm{a}) \equiv-\left[\int_{\mathrm{a}}^{\mathrm{b}} \partial_{\mathrm{u}} \Psi\left(\mathrm{u}, \mathrm{B}^{\mathrm{u}}\right)\right] /(\mathrm{b}-\mathrm{a}) \\
=\left[\Phi^{\mathrm{s}}(\mathrm{b})-\Phi^{\mathrm{s}}(\mathrm{a})\right] /(\mathrm{b}-\mathrm{a}) \equiv\left[\Psi^{\mathrm{s}}(\mathrm{a})-\Psi^{\mathrm{s}}(\mathrm{b})\right] /(\mathrm{b}-\mathrm{a}),
\end{aligned}
$$

by Prop. 4. (Equivalently, $(\mathrm{b}-\mathrm{a})\langle\mathrm{f}\rangle=\Phi\left(\mathrm{b}, \mathrm{H}^{\mathrm{b}}\right)+\Psi\left(\mathrm{a}, \mathrm{B}^{\mathrm{a}}\right)-\left(\mathrm{B}^{\mathrm{a}}, \mathrm{H}^{\mathrm{b}}\right)$.) Now bounds exist: $(\mathrm{b}-\mathrm{a})\langle\mathrm{f}\rangle \leq \Phi_{m}^{\mathrm{s}}(\mathrm{b})+\Psi_{m}^{\mathrm{s}}(\mathrm{a})+\left(\mathrm{B}^{\mathrm{s}}, \mathrm{H}^{\mathrm{s}}\right)$ (note how both expressions in (17) give this), and $-\Psi_{m}^{\mathrm{s}}(\mathrm{b})-\Phi_{m}^{\mathrm{s}}(\mathrm{a})-\left(\mathrm{B}^{\mathrm{s}}, \mathrm{H}^{\mathrm{s}}\right) \leq(\mathrm{b}-\mathrm{a})\langle\mathrm{f}\rangle$ (same remark), so we have proved what follows:

Proposition 7. The average force $\langle\mathrm{f}\rangle$ satisfies

$$
-\Psi_{m}^{\mathrm{s}}(\mathrm{b})-\Phi_{m}^{\mathrm{s}}(\mathrm{a})-\left(\mathrm{B}^{\mathrm{s}}, \mathrm{H}^{\mathrm{s}}\right) \leq(\mathrm{b}-\mathrm{a})\langle\mathrm{f}\rangle \leq \Phi_{m}^{\mathrm{s}}(\mathrm{b})+\Psi_{m}^{\mathrm{s}}(\mathrm{a})+\left(\mathrm{B}^{\mathrm{s}}, \mathrm{H}^{\mathrm{s}}\right) .
$$

[One may check that if $m$ is deleted, i.e., in the case of an exact calculation, the extreme values in (18) coincide:

$$
\begin{aligned}
\Psi^{\mathrm{s}}(\mathrm{b})+\Phi^{\mathrm{s}}(\mathrm{a})+\left(\mathrm{B}^{\mathrm{s}}, \mathrm{H}^{\mathrm{s}}\right)+\Phi^{\mathrm{s}}(\mathrm{b})+\Psi^{\mathrm{s}}(\mathrm{a})+\left(\mathrm{B}^{\mathrm{s}}, \mathrm{H}^{\mathrm{s}}\right) \\
=\Psi(\mathrm{b})+\Phi(\mathrm{a})+\left(\mathrm{B}^{\mathrm{s}}, \mathrm{H}^{\mathrm{s}}\right)-\left(\mathrm{B}^{\mathrm{b}}, \mathrm{H}^{\mathrm{s}}\right)-\left(\mathrm{B}^{\mathrm{s}}, \mathrm{H}^{\mathrm{a}}\right) \\
+\Phi(\mathrm{b})+\Psi(\mathrm{a})+\left(\mathrm{B}^{\mathrm{s}}, \mathrm{H}^{\mathrm{s}}\right)-\left(\mathrm{B}^{\mathrm{s}}, \mathrm{H}^{\mathrm{b}}\right)-\left(\mathrm{B}^{\mathrm{a}}, \mathrm{H}^{\mathrm{s}}\right) \\
=\left(\mathrm{B}^{\mathrm{b}}, \mathrm{H}^{\mathrm{b}}\right)+\left(\mathrm{B}^{\mathrm{s}}, \mathrm{H}^{\mathrm{s}}\right)-\left(\mathrm{B}^{\mathrm{b}}, \mathrm{H}^{\mathrm{s}}\right)-\left(\mathrm{B}^{\mathrm{s}}, \mathrm{H}^{\mathrm{b}}\right) \\
+\left(\mathrm{B}^{\mathrm{a}}, \mathrm{H}^{\mathrm{a}}\right)+\left(\mathrm{B}^{\mathrm{s}}, \mathrm{H}^{\mathrm{s}}\right)-\left(\mathrm{B}^{\mathrm{a}}, \mathrm{H}^{\mathrm{s}}\right)-\left(\mathrm{B}^{\mathrm{s}}, \mathrm{H}^{\mathrm{a}}\right),
\end{aligned}
$$

which is 0 , by orthogonality, cf. (4).]

Thanks to (13), we can trim the bounds in (18) to obtain

$$
\Phi_{m}^{\mathrm{s}}(\mathrm{b})-\Phi_{m}^{\mathrm{s}}(\mathrm{a})-\mathcal{F}_{\mathrm{b}} \leq(\mathrm{b}-\mathrm{a})\langle\mathrm{f}\rangle \leq \Phi_{m}^{\mathrm{s}}(\mathrm{b})-\Phi_{m}^{\mathrm{s}}(\mathrm{a})+\mathcal{F}_{\mathrm{a}}
$$

(with the obvious abbreviation $\mathcal{F}_{\mathrm{u}}$ for $\mathcal{F}_{\mathrm{u}}\left(\mathrm{B}^{\mathrm{u}}{ }_{m}, \mathrm{H}^{\mathrm{u}}{ }_{m}\right)$ ) and

$$
\Psi_{m}^{\mathrm{s}}(\mathrm{a})-\Psi_{m}^{\mathrm{s}}(\mathrm{b})-\mathcal{F}_{\mathrm{a}} \leq(\mathrm{b}-\mathrm{a})\langle\mathrm{f}\rangle \leq \Psi_{m}^{\mathrm{s}}(\mathrm{a})-\Psi_{m}^{\mathrm{s}}(\mathrm{b})+\mathcal{F}_{\mathrm{b}} .
$$


Note that the extreme values are the same in (18), (19), and (20). Since they are all computable, we thus have bilateral bounds on the average force. The width of the fork between these bounds, $\Delta\langle\mathrm{f}\rangle$, is given by

$$
(\mathrm{b}-\mathrm{a}) \Delta\langle\mathrm{f}\rangle=\mathcal{F}_{\mathrm{b}}\left(\mathrm{B}_{m}^{\mathrm{b}}, \mathrm{H}_{m}^{\mathrm{b}}\right)+\mathcal{F}_{\mathrm{a}}\left(\mathrm{B}_{m}^{\mathrm{a}}, \mathrm{H}_{m}^{\mathrm{a}}\right) .
$$

If $b-a$ is small enough, $\langle f\rangle$ approaches f. So following Matagne (2003), one gets approximate bounds for the force itself, which a priori looked like an impossible challenge. But the smaller $\mathrm{b}-\mathrm{a}$, the more precise the approximation must be, a trade-off the terms of which must be examined case by case. Since the right-hand side of (21) is determined by the accuracy of the computation (choice of mesh, etc.), the smaller $b-a$, the larger the fork around $<f>$.

There is an alternative way to proceed, which begins by first taking the averages ${ }^{\mathrm{H}}\langle\mathrm{f}\rangle_{m}$ and ${ }^{\mathrm{B}}\langle\mathrm{f}\rangle_{m}$ of the approximations ${ }^{\mathrm{H}} \mathrm{f}^{\mathrm{u}}{ }_{m}$ and ${ }^{\mathrm{B}} \mathrm{f}^{\mathrm{u}}{ }_{m}$ of $\mathrm{f}^{\mathrm{u}}$ :

$$
\begin{aligned}
& (\mathrm{b}-\mathrm{a}){ }^{\mathrm{H}}\langle\mathrm{f}\rangle_{m}=\int_{\mathrm{a}}^{\mathrm{b}} \partial_{\mathrm{u}} \Phi\left(\mathrm{u}, \mathrm{H}^{\mathrm{u}}{ }_{m}\right)=\Phi_{m}^{\mathrm{s}}(\mathrm{b})-\Phi_{m}^{\mathrm{s}}(\mathrm{a}), \\
& (\mathrm{b}-\mathrm{a}){ }^{\mathrm{B}}\langle\mathrm{f}\rangle_{m}=\int_{\mathrm{b}}^{\mathrm{a}} \partial_{\mathrm{u}} \Psi\left(\mathrm{u}, \mathrm{B}^{\mathrm{u}}{ }_{m}\right)=\Psi_{m}^{\mathrm{s}}(\mathrm{a})-\Psi^{\mathrm{s}}{ }_{m}(\mathrm{~b}),
\end{aligned}
$$

which allows one to rewrite (19)(20) as follows:

$$
(\mathrm{b}-\mathrm{a}){ }^{\mathrm{H}}\langle\mathrm{f}\rangle_{m}-\mathcal{F}_{\mathrm{b}} \leq(\mathrm{b}-\mathrm{a})\langle\mathrm{f}\rangle \leq(\mathrm{b}-\mathrm{a}){ }^{\mathrm{H}}\langle\mathrm{f}\rangle_{m}+\mathcal{F}_{\mathrm{a}}
$$

(same abbreviation $\mathcal{F}_{\mathrm{u}}$ as above) and

$$
(\mathrm{b}-\mathrm{a}){ }^{\mathrm{B}}\langle\mathrm{f}\rangle_{m}-\mathcal{F}_{\mathrm{a}} \leq(\mathrm{b}-\mathrm{a})\langle\mathrm{f}\rangle \leq(\mathrm{b}-\mathrm{a}){ }^{\mathrm{B}}\langle\mathrm{f}\rangle_{m}+\mathcal{F}_{\mathrm{b}} .
$$

Observe that (thanks to Prop. 3)

$$
(\mathrm{b}-\mathrm{a})\left[{ }^{\mathrm{H}}\langle\mathrm{f}\rangle_{m}-{ }^{\mathrm{B}}\langle\mathrm{f}\rangle_{m}\right]=\Phi_{m}^{\mathrm{s}}(\mathrm{b})-\Phi_{m}^{\mathrm{s}}(\mathrm{a})-\Psi_{m}^{\mathrm{s}}(\mathrm{a})+\Psi_{m}^{\mathrm{s}}(\mathrm{b})=\mathcal{F}_{\mathrm{b}}-\mathcal{F}_{\mathrm{a}},
$$

which can have either sign. But of course nothing like ${ }^{\mathrm{B}}\langle\mathrm{f}\rangle_{m} \leq\langle\mathrm{f}\rangle \leq{ }^{\mathrm{H}}\langle\mathrm{f}\rangle_{m}$ (which would give a bilateral bound on the force, by letting $b$ and $a$ tend to the same value) can be asserted. Remark, finally, that

$$
\left[{ }^{\mathrm{H}}\langle\mathrm{f}\rangle_{m}+{ }^{\mathrm{B}}\langle\mathrm{f}\rangle_{m}\right] / 2-\left(\mathcal{F}_{\mathrm{a}}+\mathcal{F}_{\mathrm{b}}\right) / 2(\mathrm{~b}-\mathrm{a}) \leq\langle\mathrm{f}\rangle \leq\left[{ }^{\mathrm{H}}\langle\mathrm{f}\rangle_{m}+{ }^{\mathrm{B}}\langle\mathrm{f}\rangle_{m}\right] / 2+\left(\mathcal{F}_{\mathrm{a}}+\mathcal{F}_{\mathrm{b}}\right) / 2(\mathrm{~b}-\mathrm{a}) .
$$

Therefore:

Proposition 8. The error done in evaluating $\langle\mathrm{f}\rangle$ by $\left[{ }^{\mathrm{H}}\langle\mathrm{f}\rangle_{m}+{ }^{\mathrm{B}}\langle\mathrm{f}\rangle_{m}\right] / 2$ is bounded by

$$
\left[\mathcal{F}_{\mathrm{a}}\left(\mathrm{B}_{m}^{\mathrm{a}}, \mathrm{H}_{m}^{\mathrm{a}}\right)+\mathcal{F}_{\mathrm{b}}\left(\mathrm{B}_{m}^{\mathrm{b}}, \mathrm{H}_{m}^{\mathrm{b}}\right)\right] / 2(\mathrm{~b}-\mathrm{a})
$$

\section{CONCLUSION}

Complementarity of magnetic energy and coenergy makes it possible to find bilateral bounds to some quantities of interest, such as inductances, capacitances, etc. This follows from old work by Noble and Synge (1957) and has been known for long 
(Anderson et al. 1969, Hammond and Penman 1976). Not all global values can thus be estimated from both sides, however, especially if one tries to move from static to dynamic situations (Bossavit 1992). In the case of forces, whose expression is the same in dynamics, the obstruction is of a different character, due to the fact that inequalities cannot, in general, be differentiated. This gives all its interest to Matagne's method to bound averages of forces over some range of variation of the configuration parameter. Proofs for such bounds have been given here.

In the general case where $\mathrm{u}$ spans a manifold $\mathrm{U}$, all this still holds, provided one replaces $(\mathrm{b}-\mathrm{a})\langle\mathrm{f}\rangle$ by the work $\int_{0}^{1}<\mathrm{f}_{\mathrm{u}} ; \partial_{\mathrm{t}} \mathrm{u}>\mathrm{dt}$ performed when passing from state $a$ to state $b$ by a trajectory $\mathrm{t} \rightarrow \mathrm{u}(\mathrm{t})$ such that $\mathrm{u}(0)=\mathrm{a}$ and $\mathrm{u}(1)=\mathrm{b}$. That $\Phi^{\mathrm{s}}$ and $-\Psi^{\mathrm{s}}$ are "functions of forces" explains why the work does not depend on which path is followed. It is more remarkable that the same be true of the bounds. This is so because, according to (16) and Prop. 5, $\Phi_{m}^{\mathrm{s}}$ and $\Psi_{m}^{\mathrm{s}}$ also are functions of forces for the approximations ${ }^{\mathrm{H}} \mathrm{f}^{\mathrm{u}}{ }_{m}$ and ${ }^{\mathrm{B}} \mathrm{f}^{\mathrm{u}}{ }_{m}$ of $\mathrm{f}^{\mathrm{u}}$.

\section{REFERENCES}

Anderson, N., Arthurs, A. M. and Robinson, P. D. (1969): "Pairs of Complementary Variational Principles", J. Inst. Maths Applics 5, 422-431.

Bossavit, A. (1992): "On complementary formulations in steady-state eddy-currents theory", IEE Proc. $A$ 139(6), 265-272.

Bossavit, A. (2004: "Forces inside a magnet", International Compumag Society Newsletter 11(1), 4-12.

Coulomb, J.L. (1983): "A methodology for the determination of global electromechanical quantities from a finite element analysis and its application to the evaluation of magnetic forces, torques and stiffness", IEEE Trans. Magn. 19(6), 2514-2519.

Hammond, P., Penman, J. (1976): "Calculation of inductance and capacitance by means of dual energy principles", Proc. IEE 123(6), 554-559.

Matagne, E. (2004): "Magnetic force and torque calculations from complementary or self-dual approaches: A coenergy-based methodology toward full accuracy control", Eur. J. Appl. Phys. 25(2), 107-115.

Penfield Jr., P., Spence, R. and Duinker, S. (1970): Tellegen's theorem and electrical networks. Cambridge (Ma), The MIT Press.

Rockafellar, R. T. (1970): Convex Analysis, Princeton, Princeton U. P.

Synge, J. L. (1957): The Hypercircle in Mathematical Physics, Cambridge, Cambridge U.P. 